DE

M E D I C I N A

T R O P I C A L

$\mathrm{DE}$

S ÃO PAULO

JOURNAL OF THE SÃO PAULO INSTITUTE OF TROPICAL MEDICINE

${ }^{1}$ Faculdade de Medicina de Marília, Departamento de Parasitologia, Marília, São Paulo, Brazil

'Universidade de Marília, Grupo de Estudo em Envelhecimento e Obesidade, Marília, São Paulo, Brazil

${ }^{3}$ Universidade Federal do ABC, Centro de Ciências Naturais e Humanas, São Bernardo do Campo, São Paulo, Brazil

${ }^{4}$ Faculdade de Medicina de Itajubá, Disciplina de Metodologia Científica, Itajubá, São Paulo, Brazil

${ }^{5}$ Universidade de Marília, Faculdade de Medicina, Marília, São Paulo, Brazil

Correspondence to: Luciamáre Perinetti Alves Martins

Faculdade de Medicina de Marília, Departamento de Parasitologia, Avenida Monte Carmelo, 800, Fragata, CEP 17519-030, Marília, SP, Brazil

E-mail: luciamarepam@gmail.com

Received: 20 May 2020

Accepted: 15 September 2020

\section{Spatio-temporal distribution of human American visceral leishmaniasis in the Western region of Sao Paulo State, from 2004 to 2018}

\author{
Eduardo Alexandre Rancan ${ }^{(1)}$, Eduardo Federighi Baisi Chagas ${ }^{\circledR 2}$, Márcia \\ Aparecida Sperança ${ }^{\circledR 3}$, Valeria Camargo de Lacerda Carvalho ${ }^{(14}$, Luciamáre \\ Perinetti Alves Martins ${ }^{(1)}$, Rodrigo Buzinaro Suzuki ${ }^{(1,5}$
}

\section{ABSTRACT}

Leishmaniasis comprises a group of zoonotic diseases caused by protozoa belonging to the Leishmania genus, noting that the visceral form is the most severe and lethal, if untreated. Nowadays visceral leishmaniasis is widespread in Brazil and the Adamantina microregion, located in the west of Sao Paulo State, has been affected by Human American Visceral Leishmaniasis (HAVL) since 2004. We evaluated the epidemiological profile of HAVL in the Adamantina microregion through a Geographic Information Systems (GIS) and established its incidence rate by location and time. Notified cases were provided by the Sao Paulo State Epidemiological Surveillance Center. Home addresses of patients who tested positive to HAVL were converted into geographic coordinates through the Google Geocoding Application Programming Interface submitted to ArcMap 10.5 System for georeferencing. Kernel spatial analyses were performed to obtain the incidence distribution and the total area involvement rate. From 2004 to 2018, 325 cases of HAVL were diagnosed in 11 of the 12 municipalities belonging to the of Adamantina microregion. The disease has disseminated to the Northwest and East-Southeast directions, taking place along the Comandante Joao Ribeiro de Barros highway, with higher incidences rates in the municipalities where the highway passes. HAVL incidence was higher in children aged between 0 to 9 years and in the elderly; there was no difference in relation to sex and the majority of cases were located in urban areas. The determination of the epidemiological profile and the the spread of disease patterns can indicate possible areas of vulnerability, in order to contribute to the management and prevention of the disease through a strategic resources optimization.

KEYWORDS: Visceral leishmaniasis. Kernel density. Incidence. Risk factors. Epidemiology. Georeferencing.

\section{INTRODUCTION}

Leishmaniasis, a group of infectious diseases caused by protozoa of the genus Leishmania, can affect humans, domestic and wild animals around the world ${ }^{1}$. These protozoa are transmitted by small insects belonging to genus Phlebotomus (in the Old World) and Lutzomyia (in the New World - Americas). Clinical manifestation of human leishmaniasis are divided into visceral and tegumentary forms depending on the infectious Leishmania species, specific geographical distributions, and the host's immunological status ${ }^{1}$.

Visceral leishmaniasis is the most severe form of the disease, being lethal in $95 \%$ of untreated cases ${ }^{2}$. This disease is part of the group of neglected infectious diseases 
worldwide, as they mainly affect low socioeconomic populations with restricted access to health services, therefore being more vulnerable ${ }^{3}$.

The first reference that visceral leishmaniasis would be endemic in Brazil was made by Penna in 1934, who found amastigotes in biopsies of 41 fatal cases with suspected Yellow Fever, living in eight States of the Northeastern, North and Midwest regions ${ }^{4}$. Subsequently, the Northeast region became endemic for human American visceral leishmaniasis (HAVL) in the country, and the first epidemic dates back to 1950 in Ceara State, presenting with persistent high lethality that has been recently verified, and in 1980 the disease gained expressiveness with the dispersion to other influential States of this region $^{4-7}$. In this period, the Northeast region accounted for 93\% of the total cases in Brazil, which were concentrated in rural areas in line with the wild behavior of the transmission vectors ${ }^{6}$.

The proximity of rural and urban areas associated with the adaptation of phlebotomines species to urban settings resulted in cases of HAVL in the city of Terezina located in Piaui State ${ }^{6}$. In Pernambuco State, the essentially rural disease paradigm shift was observed in the 1990s, with consequent expansion of the disease to new areas ${ }^{8,9}$. The dissemination of phlebotomine vectors, especially Lutzomyia longipalps and the migration of the population along with domestic dogs infected by Leishmania infantum resulted in the dissemination of HAVL to others regions of the North, Midwest and Southeast of Brazil ${ }^{10,11}$, decreasing the representativeness of the number of cases in the Northeast that reported $43.1 \%$ of them in the country, in $2012^{12}$. Currently, the HAVL occurs in 22 Brazilian States distributed among the five major Brazilian regions, presenting with social, geographical and climate particularities ${ }^{13}$.

In the West of Sao Paulo State, the first cases of HAVL were reported in urban areas in 1999, then quickly disseminating to neighboring municipalities following the spread and the transmission potential of the vector Lutzomyia longipalpis sandfly, found in this region of the State ${ }^{14,15}$.

Besides the vector density and its dissemination capacity, another major factor that may increase the complexity of transmission in this region is the proximity between municipalities ${ }^{16}$. Furthermore, changes in the economical activity leading to an increasing flow of goods and people through the highways in Western municipalities of the State are also suggested as causes for the vector and the HAVL increments ${ }^{15}$.

The city of Adamantina is located in a microregion affected by HAVL since 2004, and it was the source of dissemination of the disease ${ }^{17}$, due to its proximity to a secondary highway. In this way, building an epidemiological profile based on spatial and temporal analyses, with determination of incidence rates, in addition to associated environmental and socioeconomical characteristics, is a crucial mechanism in the development of disease control strategies ${ }^{18}$. In this sense, this work aimed to conceive a spatial and temporal distribution of HAVL in the municipalities of the Adamantina microregion, since its onset in 2004, until 2018, through georeferencing and then to verify the pattern of disease distribution, as well as

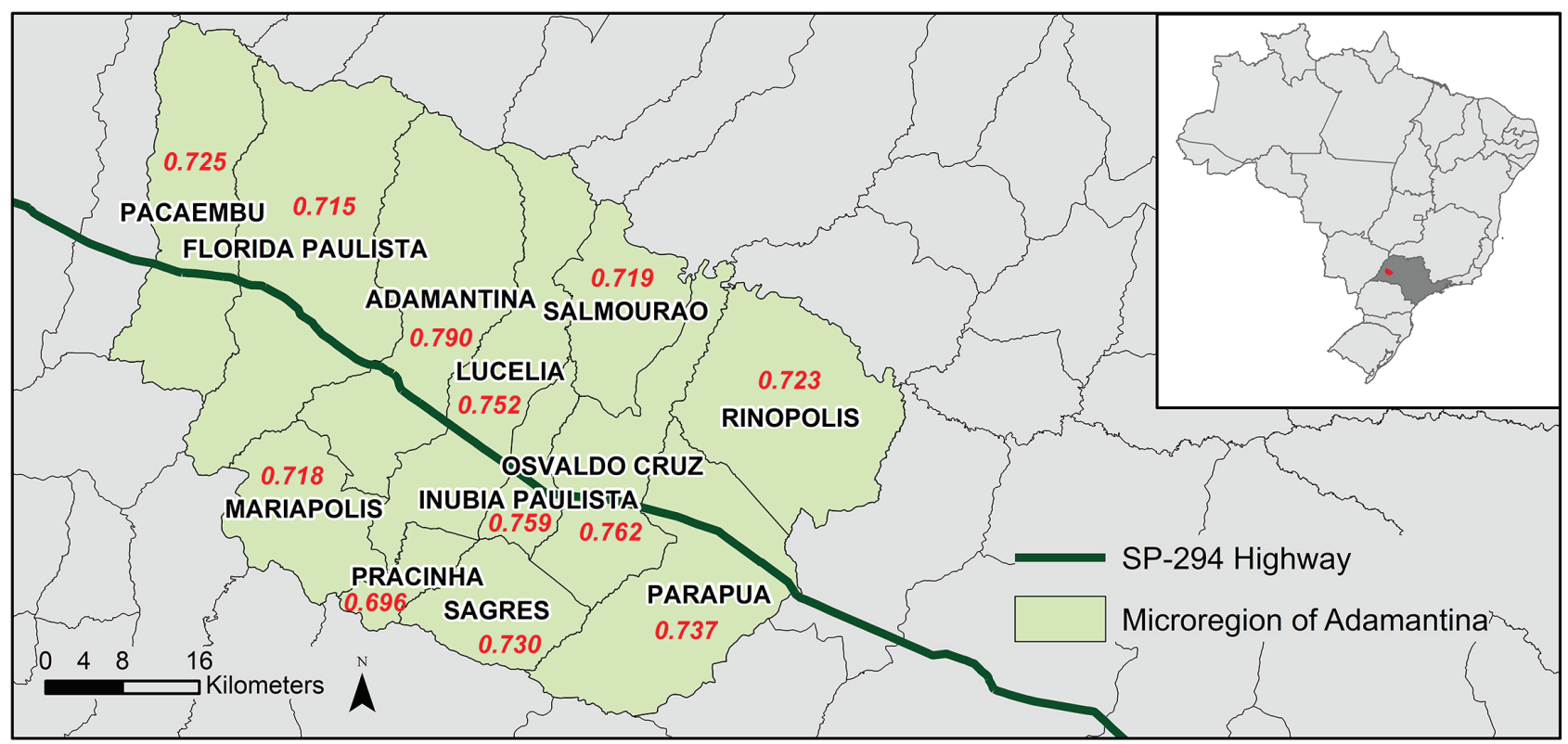

Figure 1 - Study area showing the Adamantina microregion, its geographic location in Sao Paulo State and in Brazil; highway Comandante Joao Ribeiro de Barros (SP-294); the HDI of each municipality is highlighted in red. 

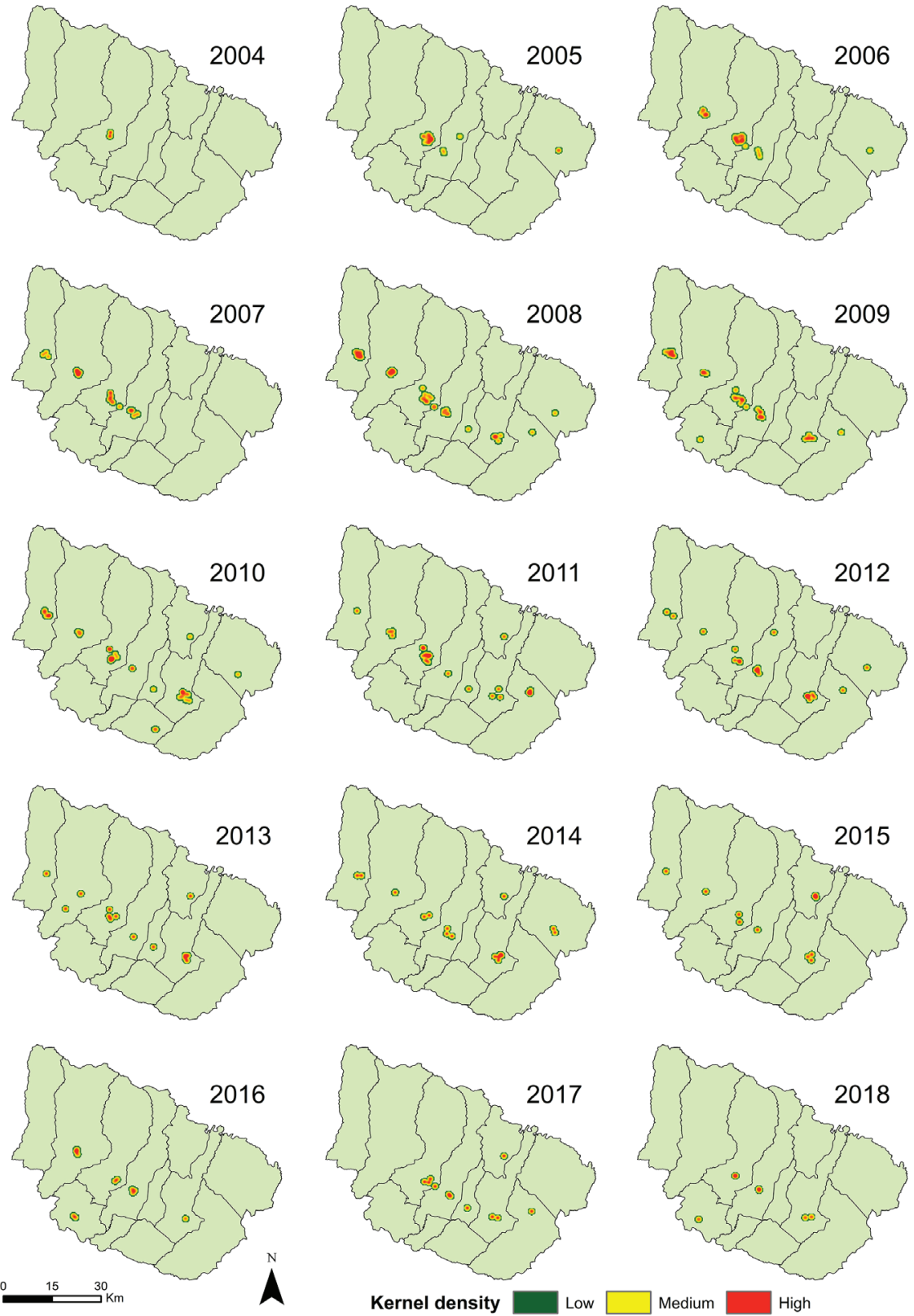

Figure 2 - Geographic distribution of Human American Visceral Leishmaniasis cases in the microregion of Adamantina per year, from 2004 to 2018. Confirmed cases are expressed as incidences and represented by the Kernel density.

the possible areas of vulnerability in order to contributing to the management and prevention of the disease through strategic resources optimization.

\section{METHODS}

\section{Study area}

As part of the municipalities of the Adamantina microregion, which is inserted in the Presidente Prudente mesoregion, Western region of the Sao Paulo State, are members of the Epidemiological Surveillance Group
(GVE), region XIX - Marilia: Pacaembu, Florida Paulista, Adamantina, Mariapolis, Lucelia, Pracinha, Inubia Paulista, Sagres, Osvaldo Cruz, Parapua, Salmourao and Rinopolis. This microregion covers an area of $3,445,789 \mathrm{~km}^{2}$ and 149,066 inhabitants, based on the last census of the Brazilian Institute of Geography and Statistics (IBGE) ${ }^{19}$ in 2010 and a range of HDI - Human Development Index - mostly within the higher range (from 0.700 to 0.799 ). This census was also used to record each municipality population. Annual rainfall data of the municipality of Adamantina was used for the meteorological referencing of the microregion, obtained by the Integrated Center of 
Agrometeorological Information of the Agronomic Institute of the Secretariat of Agriculture and Supply - CIIAGRO ${ }^{20}$.

\section{Human LV cases}

This research is an observational, longitudinal and retrospective quantitative study. Excel files, provided by the Epidemiological Surveillance Center (CVE) "Prof. Alexandre Vranjac" of the Sao Paulo State Health Department, were used as collection instruments, referring to the HAVL, between 2004 to 2018, which were stratified and used according to the variables: date of notification, municipality code of residence, age, sex, residence address, neighborhood and classification of the diagnosis. Thereafter, the column data referring to the addresses of the respective confirmed cases were converted into geographic coordinates using the Google Geocoding API (Application Programming Interface). The ordered pairs of coordinates were added to the notification numbers, which allowed the georeferencing with a high precision, by plotting the cases on a surface previously delimited by the municipal limits using the ArcMap software (version 10.5, ESRI, California, USA). In order to generate a surface that approximates the studied phenomenon in a realistic way, the plotted confirmed cases were treated using the Kernel density phenomenon smoothing methodology for geographic representation purposes. The radius of influence that defines the degree of vicinity of the points was established in order to generate a 1000 square-meters area. All data treated with the Kernel tool had in its ratio the corresponding population of each municipality.

\section{Statistical analysis}

Qualitative variables were described by the distribution of absolute (N) and relative (\%) frequencies. The proportion of cases in total and by region was analyzed by the incidence rate, which was calculated by dividing the number of confirmed cases by the aggregate of exposed population in the period and results were expressed per 100,000 inhabitants. The $95 \%$ confidence interval $(95 \%$ CI) for the incidence rate was calculated using the equation $p \pm 1.96 \times \sqrt{ } p \times q / n$, where " $p$ " represents the incidence rate, " $q$ " represents the complementary incidence rate $(q=1-p)$, and " $n$ " represents the sample size. Significant differences between the incidence rates were considered when there was no overlapping of the $95 \%$ CI. The normality distribution was analyzed using the Shapiro-Wilk test. The relationship between quantitative variables was analyzed using the Pearson's correlation test. The percentage of variation of the dependent variable (y-axis) explained by the variation of the independent variable ( $\mathrm{x}$-axis) was analyzed by the linear $\mathrm{R} 2$. The level of significance adopted was $5 \%(\mathrm{p} \leq 0.05)$. The data were analyzed using the SPSS software (version 22.0 IBM, Armonk, New York, USA).

\section{Ethical approval}

This research was approved by the Human Research Ethical Committee of Marilia Medical School, process $n^{\circ}$ 21430413.6.0000.5413.

\section{RESULTS}

During the analyzed period, 325 cases of HAVL were diagnosed in the municipalities of the Adamantina microregion, as shown in Table 1. Of these cases, 316 $(97.23 \%)$ had complete addresses information and were georeferenced. Nine cases $(2.77 \%)$ were from rural areas, and among them, only three were correctly georeferenced. The highest absolute incidence was observed in the municipality of Adamantina with 108 confirmed cases, followed by 50 cases in the municipality of Osvaldo Cruz. During the studied period, no positive cases were registered in the municipality of Pracinha.

Table 1 - Incidence of Human American Visceral Leishmaniasis per year in the municipalities of the microregion of Adamantina, Sao Paulo State, from 2004 to 2018.

\begin{tabular}{cccc}
\hline Year & Case number & \multicolumn{2}{c}{$\begin{array}{c}\text { Incidence per } 100.000 \\
\text { inhabitants }(\text { IC95\%) }\end{array}$} \\
\hline 2004 & 2 & 1.3 & $(0.4 / 4.9)$ \\
2005 & 23 & 15.4 & $(10.3 / 23.1)$ \\
2006 & 28 & 18.8 & $(13.0 / 27.1)$ \\
2007 & 24 & 16.1 & $(10.8 / 24.0)$ \\
2008 & 51 & 34.2 & $(26.0 / 45.0)$ \\
2009 & 36 & 24.2 & $(17.4 / 33.4)$ \\
2010 & 41 & 27.5 & $(20.3 / 37.3)$ \\
2011 & 24 & 16.1 & $(10.8 / 24.0)$ \\
2012 & 22 & 14.8 & $(9.7 / 22.3)$ \\
2013 & 17 & 11.4 & $(7.1 / 18.3)$ \\
2014 & 16 & 10.7 & $(6.6 / 17.4)$ \\
2015 & 11 & 7.4 & $(4.1 / 13.2)$ \\
2016 & 12 & 8.1 & $(4.6 / 14.1)$ \\
2017 & 11 & 7.4 & $(4.1 / 13.2)$ \\
2018 & 7 & 4.7 & $(2.3 / 9.7)$ \\
\hline Total & 325 & 14.5 & $(13.0 / 16.2)$ \\
\hline
\end{tabular}

The temporal distribution of the microregion HAVL cases per year and their respective incidence calculations 
showed two peaks with a statistically significant difference in relation to the previous year, according to the established confidence interval, being one in 2005 , with 15.4 cases per 100,000 inhabitants; and the other in 2008, with 34.2 cases per 100,000 inhabitants (Table 1). It is noteworthy that 2008 was the year with the highest recorded incidence. However, in 2005, the municipality of Adamantina deserves special attention due to the incidence attributed to the microregion, as it concentrated around 18 confirmed cases, in absolute numbers, corresponding to an incidence of approximately 50 cases per 100,000 inhabitants. In 2008 , the municipality of Pacaembu deserves to be mentioned, due to 14 confirmed cases in absolute numbers and an incidence of 100 cases per 100,000 inhabitants.

However, as of 2010 , there was a decrease in the incidence of HAVL autochthonous cases in the microregion, and in 2018, only seven cases were reported in three municipalities, corresponding the lowest incidence in the period, of 4.7 cases per 100,000 inhabitants (Table 1).
Figure 3 shows the expansion of human cases of HAVL in the microregion, which began in 2004 with the finding of amastigote forms in bone marrow aspirates of two patients living in the municipality of Adamantina. The following year, positive cases were detected in the cities of Lucelia and Rinopolis, $6 \mathrm{~km}$ and $48 \mathrm{~km}$ from Adamantina, respectively. In subsequent years, the disease was established, in the Northwest and East-Southeast directions, with cases in 2006 recorded in the municipality of Florida Paulista, in 2007 in the municipality of Pacaembu and, in 2008, in the municipalities of Inubia Paulista, Osvaldo Cruz and Parapua.

The density raster indicates a predominance of confirmed cases in urban areas in relation to rural areas, as shown in Figure 3. Municipalities that are crossed by the Comandante Joao Ribeiro de Barros highway (SP - 294), such as Florida Paulista, Adamantina, Pacaembu and Lucelia, had the highest incidence rates, in that order. No statistically significant difference was observed for the incidence of

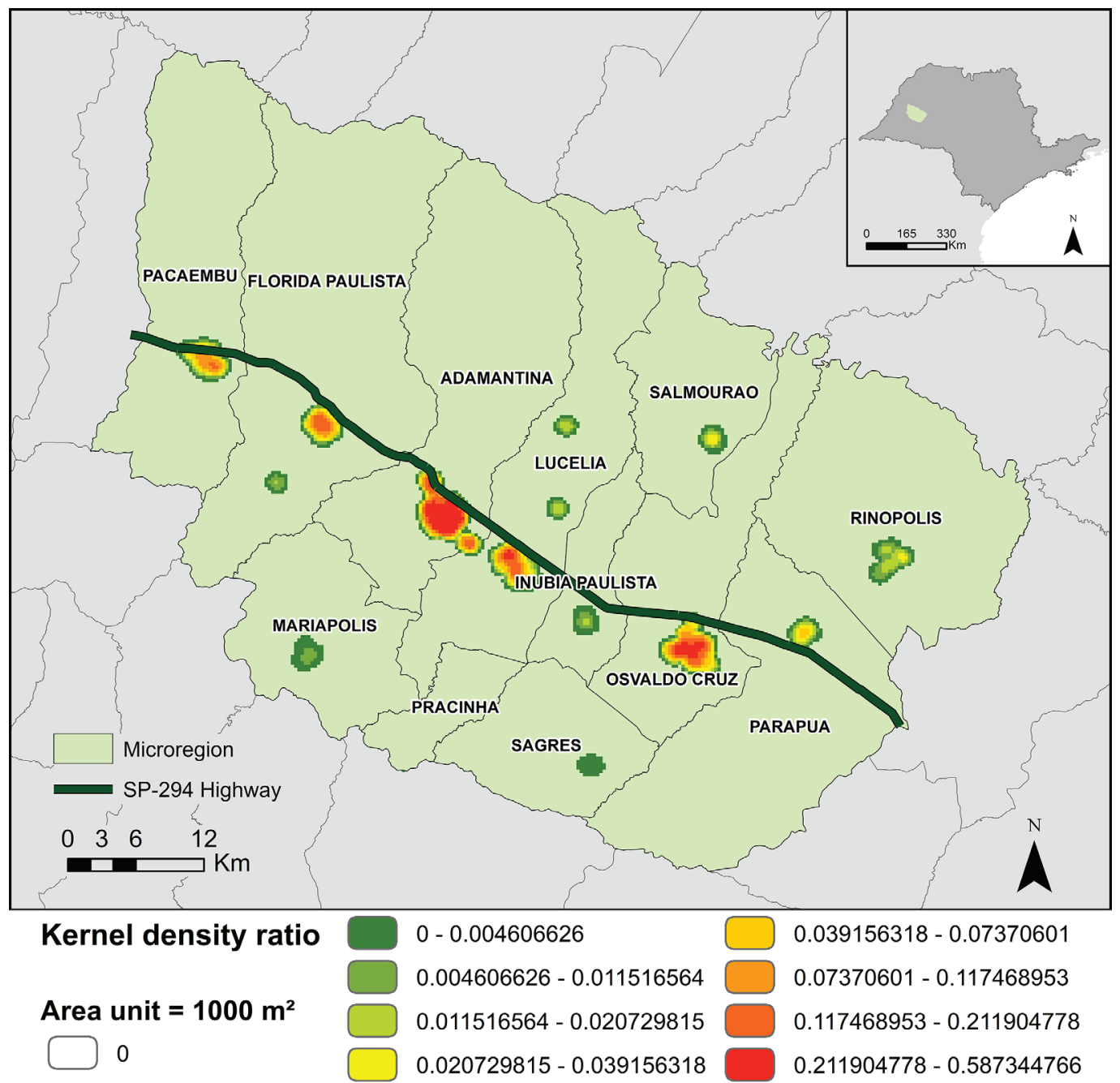

Figure 3 - Geographic distribution of Human American Visceral Leishmaniasis cases in the Adamantina microregion from 2004 to 2018, expressed by the Kernel density ratio. 
HAVL between the municipalities of Adamantina, Florida Paulista, Lucelia, Pacaembu and Inubia Paulista, which are interconnected by the Comandante Joao Ribeiro de Barros highway. However, the municipalities of Adamantina, Florida Paulista and Pacaembu showed a statistically significant $(95 \% \mathrm{CI})$ difference regarding the incidence of confirmed cases of HAVL in relation to the municipalities of Rinopolis, Osvaldo Cruz and Parapua. The municipality of Mariapolis also had a low incidence rate, however, it showed a statistically significant difference only in the municipalities of Adamantina and Florida Paulista.

The municipalities of Adamantina and Florida Paulista had a higher incidence and statistical significance in the microregion (Table 2), whereas, Rinopolis and Parapua had lower incidences and statistical significance. Nevertheless, given the high amplitude of confidence intervals of the municipalities with the lowest populations, the municipalities of Osvaldo Cruz, Inubia Paulista, Lucelia and Parapua did not present a statistically significant difference in relation to Mariapolis and Rinopolis. In relation to sex, only in the municipality of Osvaldo Cruz a significant difference was observed. In the microregion, this difference could not be established, emphasizing that the incidence calculations were performed based on the population according to the 2010 IBGE sense.

The Pearson's correlation coefficient revealed no influence of annual rainfall index on the HVAL incidence, as seen in Figure 4. Regarding the demographic analysis, it was observed that the age group from 0 to 9 years old had a higher incidence compared to the others, with 47.4 cases per 100,000 inhabitants, followed by the age group above 59 years, with an incidence of 14.7 per 100,000 inhabitants.

Table 2 - Relationship between the incidence of Human American Visceral Leishmaniasis by municipality, sex and the total of the microregion of Adamantina, Sao Paulo State, from 2004 to 2018.

\begin{tabular}{|c|c|c|c|c|c|c|}
\hline \multirow{2}{*}{ Municipalities } & \multicolumn{2}{|c|}{ Female } & \multicolumn{2}{|c|}{ Male } & \multicolumn{2}{|c|}{ Total } \\
\hline & Case $N^{\circ}$ & Incidence ${ }^{*}$ & Case $\mathrm{N}^{\circ}$ & Incidence ${ }^{*}$ & Case $\mathrm{N}^{\circ}$ & Incidence ${ }^{*}$ \\
\hline Adamantina & 45 & $\begin{array}{c}17.2 \\
(12.9 / 23.0)\end{array}$ & 63 & $\begin{array}{c}25.6 \\
(20.0 / 32.7)\end{array}$ & 108 & $\begin{array}{c}21.3 \\
(17.6 / 25.7)\end{array}$ \\
\hline Florida Paulista & 21 & $\begin{array}{c}24.2 \\
(15.8 / 36.9)\end{array}$ & 24 & $\begin{array}{c}22.7 \\
(15.2 / 33.7)\end{array}$ & 45 & $\begin{array}{c}23.3 \\
(17.5 / 31.2)\end{array}$ \\
\hline Inubia Paulista & 1 & $\begin{array}{c}3.7 \\
(0.7 / 20.9)\end{array}$ & 4 & $\begin{array}{c}14.7 \\
(5.7 / 37.9)\end{array}$ & 5 & $\begin{array}{c}9.2 \\
(3.9 / 21.5)\end{array}$ \\
\hline Lucelia & 20 & $\begin{array}{c}14.3 \\
(9.3 / 22.1) \\
\end{array}$ & 24 & $\begin{array}{c}15.2 \\
(10.2 / 22.5) \\
\end{array}$ & 44 & $\begin{array}{c}14.8 \\
(11.0 / 19.8)\end{array}$ \\
\hline Mariapolis & 1 & $\begin{array}{c}3.5 \\
(0.6 / 19.9) \\
\end{array}$ & 3 & $\begin{array}{c}9.9 \\
(3.4 / 29.1)\end{array}$ & 4 & $\begin{array}{c}6.8 \\
(2.6 / 17.5) \\
\end{array}$ \\
\hline Osvaldo Cruz & 15 & $\begin{array}{c}6.5 \\
(3.9 / 10.7)\end{array}$ & 35 & $\begin{array}{c}15.0 \\
(10.8 / 20.9)\end{array}$ & 50 & $\begin{array}{c}10.8 \\
(8.2 / 14.2)\end{array}$ \\
\hline Pacaembu & 13 & $\begin{array}{c}15.9 \\
(9.3 / 27.2)\end{array}$ & 27 & $\begin{array}{c}23.2 \\
(16.0 / 33.8)\end{array}$ & 40 & $\begin{array}{c}20.2 \\
(14.8 / 27.5)\end{array}$ \\
\hline Rinopolis & 4 & $\begin{array}{c}5.5 \\
(2.1 / 14.0)\end{array}$ & 4 & $\begin{array}{c}5.3 \\
(2.1 / 13.6)\end{array}$ & 8 & $\begin{array}{c}5.4 \\
(2.7 / 10.6)\end{array}$ \\
\hline Sagres & 1 & $\begin{array}{c}5.5 \\
(1.0 / 31.4)\end{array}$ & 1 & $\begin{array}{c}5.6 \\
(1.0 / 31.7)\end{array}$ & 2 & $\begin{array}{c}5.6 \\
(1.5 / 20.3)\end{array}$ \\
\hline Salmourao & 5 & $\begin{array}{c}14.2 \\
(6.1 / 33.3) \\
\end{array}$ & 4 & $\begin{array}{c}10.8 \\
(4.2 / 27.7) \\
\end{array}$ & 9 & $\begin{array}{c}12.5 \\
(6.6 / 23.7) \\
\end{array}$ \\
\hline Parapua & 6 & $\begin{array}{c}7.5 \\
(3.5 / 16.4)\end{array}$ & 4 & $\begin{array}{c}4.8 \\
(1.9 / 12.4)\end{array}$ & 10 & $\begin{array}{c}6.1 \\
(3.3 / 11.3)\end{array}$ \\
\hline Microregion & 132 & $\begin{array}{c}12.3 \\
(10.4 / 14.6)\end{array}$ & 193 & $\begin{array}{c}16.6 \\
(14.4 / 19.1)\end{array}$ & 325 & $\begin{array}{c}14.5 \\
(13.0 / 16.2)\end{array}$ \\
\hline
\end{tabular}

The Municipality of Pracinha is not described in Table 2 because it did not present confirmed cases during the studied period; *Incidence per 100,000 inhabitants (95\% Cl) 

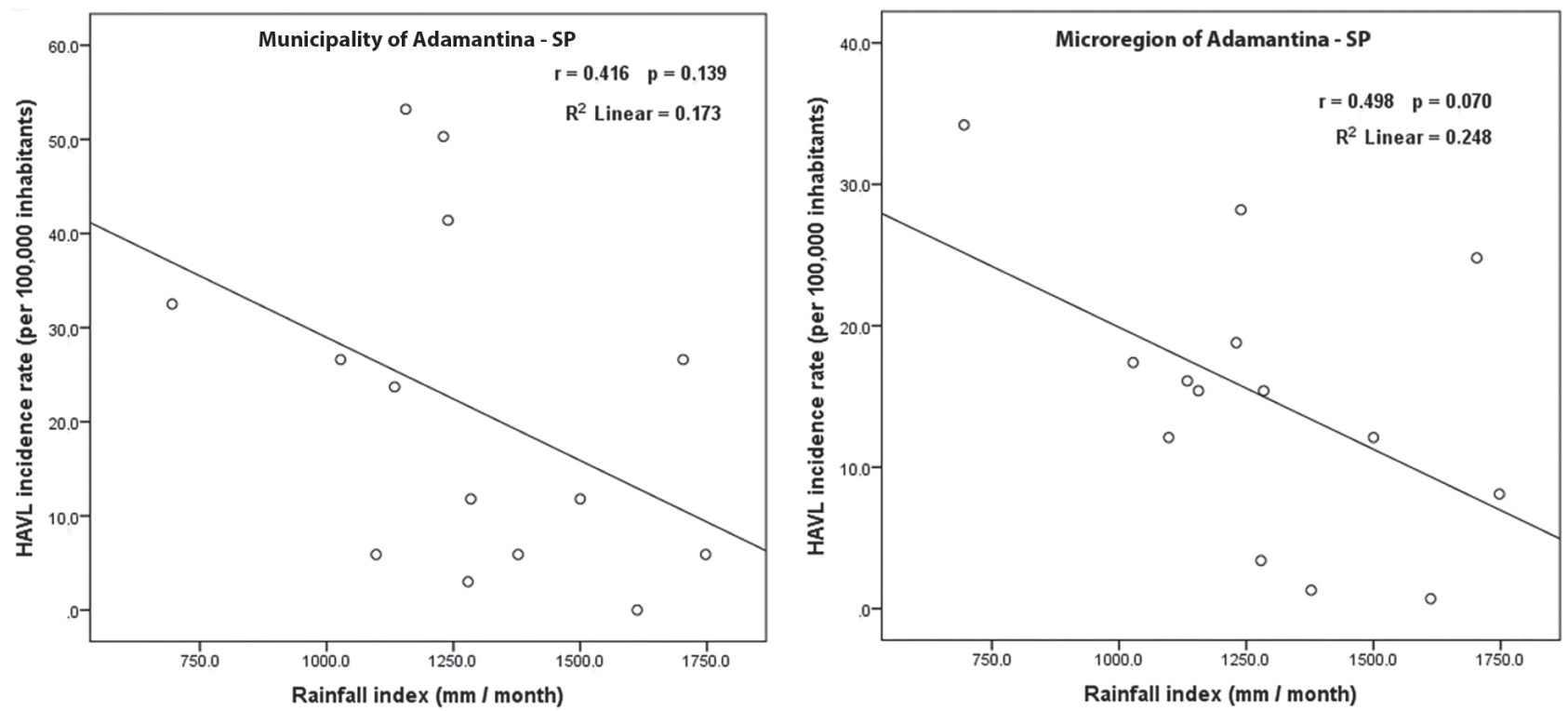

Figure 4 - Relationship between rainfall indexes and Human American Visceral Leishmaniasis incidence in Adamantina, Sao Paulo State, and Adamantina, Sao Paulo State microregion, from 2004 to 2015. The Pearson's correlation coefficient (r); $p$ value calculated by the Pearson's correlation test. Linear R2 = percentage of variation of the dependent variable ( $y$-axis) explained by the variation of the independent variable (x-axis).

The first presented a statistical significance difference in relation to all other groups, and the second presented a statistical significant difference in relation to the group from 20 to 59 years old (Table 2).

\section{DISCUSSION}

In 2003, dogs infected by visceral leishmaniasis were reported in Adamantina microregion for the first time in the municipality of Lucelia, then, one-year latter, in 2004, the municipality of Adamantina presented the first confirmed human case, corroborating that infection in dogs precede the occurrence of HAVL, in concordance with its previously described classical dispersion pattern, as well as their importance from an epidemiological point of view ${ }^{11,21,22}$.

Since then, HAVL has spread to 11 of the 12 municipalities in this area, reaching the highest number of notifications in 2008, with an incidence of 34.2 cases per 100,000 inhabitants. Although the municipalities of this microregion are relatively similar in terms of HDI, and also regarding the climate and altitude, all aspects that show importance within the scope of risk factors for HALV transmission, were not relevant in this study when compared to geographic factors ${ }^{14}$.

The georeferencing of HAVL cases in the Adamantina microregion argues in favor of a correlation between municipalities with higher disease incidence and the proximity to the secondary Highway Comandante Joao Ribeiro de Barros (SP-294), suggesting that this highway has an important role in HAVL dispersion.
Although some studies ${ }^{14,15,23}$ have pointed Marechal Rondon highway as the main pathway of spreading the disease due to its intense flow of people and goods, departing from Aracatuba and heading towards Bauru, in the present study it was observed that the secondary roads were equally important in the dispersion of the disease in the Western Sao Paulo region, since the first reports of human cases in the city of Bauru in $2003^{24}$ and in the municipality of Adamantina in 2004. Hence, our results suggest that the spread of HAVL in this West region of Sao Paulo State followed a centrifugal dissemination pattern, as observed by Toledo et al..$^{25}$ in Araguaina, Tocantins State.

The spatial analysis showed that the spread of HAVL along the SP-294 road occurred in the East-Southeast direction, with progressive dispersion of autochthonous cases. Although other municipalities, which are not part of the Adamantina microregion, but belong to GVE-XIX and are interconnected by this highway were not the subject of this study, it was observed that, in 2010, the first autochthonous case of HAVL was notified in the municipality of Bastos; in 2012, in the municipality of Tupa; in 2013, in Quintana and Pompeia; in 2014 in the city of Marilia; and, finally, in 2019, in the municipality of Garca (CVE).

The comparison of GVE-XIX (Marilia), which belongs to the Adamantina microregion, with the other neighboring GVEs, such as GVE-XI (Aracatuba), GVE-XV (Bauru), GVE-XXI (Presidente Prudente) and GVE-XXII (Presidente Venceslau), found a lower incidence in the first municipality in relation to the others. However, considering 
the number of reported cases, as well as the populations, the analysis of the Adamantina microregion found higher incidence rates, both within its GVE and in relation to the borderline municipalities, demonstrating the importance of this microregion as an incipient endemic region in Sao Paulo State. This fact probably occurred due to the proximity between the municipalities interconnected by SP-294, facilitating the intense flow of residents, as the most affected municipalities that are crossed by it presented statistically significant differences in the incidence of cases when compared with the municipalities of Mariapolis, Rinopolis and Pracinha, and the latter did not present confirmed cases of the disease. In addition, our Kernel density raster follows the SP-294 direction, showing the most affected areas in the accumulated period.

An elevated rainfall index is an important environmental factor of HAVL as it significantly increases the population of sandflies ${ }^{26}$. Despite that, our data revealed no correlation, either positive or negative, between rainfall indexes and HAVL incidences, decreasing the most relevant environmental factor related to the climate involved in the disease, both in propagation and in perpetuation.

Another factor that has probably influenced the high incidence of the disease in this microregion is the sociodemographic characteristics of the municipalities. They are small, with an average of 12,422 inhabitants that preserve rural characteristics and habits, most residences have fruit trees and livestock, such as chickens and ducks that are used as natural predators of the endemic scorpions in the region ${ }^{27}$. Thus, there is an ideal environment for the development and dispersal of the vector insect, similar to the situation reported by Vieira et $a l .^{28}$ in the municipality of Birigui.

As mentioned by other authors ${ }^{29,30}$, it was found that most cases of HAVL were concentrated in the urban perimeter of the municipalities and, despite a higher prevalence of the disease in males in others regions of Sao Paulo State ${ }^{23,31}$, no significant difference between genders was observed in the studied microregion, corroborating the results obtained by Vieira et al. ${ }^{28}$ in Birigui, Sao Paulo State, and Moura et al. ${ }^{32}$ in the island of Sao Luis, Maranhao State. The HAVL equal incidence between genders can be attributed to the predominance of urban cases, an environment in which there is no tendency for men to be more exposed to a harsh environment than women ${ }^{28}$, unlike the situation in rural areas ${ }^{33}$.

Regarding the age group, a higher incidence was found in children up to 9 years old and in adults over 59 years old, but the highest lethality was observed in adults between 20 and 59 years old. According to Queiroz et al. ${ }^{34}$, the greater the number of cases in a region, the higher the vulnerability of infected children, who have an immature cellular immune response, in the same way of the elderly, who also show an immune response decline with advancing age, beyond comorbidities, such as chronic diseases that worsen the prognosis in these individuals and justify the increased incidence in both age ranges ${ }^{35,36}$.

Although there are reports of HAVL seasonality ${ }^{23}$, this research could not detect this phenomenon, reported by Lopes et al. ${ }^{37}$ in Belo Horizonte, Minas Gerais State. Among some possibilities, we highlight the short period of time since the onset of the disease in this microregion.

After the establishment of HAVL prevention and control measures, a decrease in the number of cases has been observed since 2010, what may have occurred in association with the "Visceral Leishmaniasis Control Program", which classifies the regions according to areas with confirmed HAVL cases and silent ones. They can also be classified as vulnerable, as they are contiguous municipalities with others with confirmed cases of HAVL and / or are interconnected by the same important road axis between endemic municipalities ${ }^{38}$. Given the geographic distribution shown in this research, municipalities in the West of Sao Paulo State contiguous to all those cities, or presenting with confirmed cases, as well as those connected by SP-294 and that have not yet presented cases of HAVL, fall into this category of vulnerability, requiring preventive control strategies ${ }^{28,37,39}$.

Furthermore, the implementation of prevention and control measures at the municipal level are hampered by the intermittency of the measures, sometimes due to financial factors, sometimes due to dengue epidemics, as these situations depend on the same team and municipal resources used in health problems. In addition, the prevalence of American visceral leishmaniasis-seropositive dogs whose tutors resist to deliver them to euthanasia and various other reasons such as the difficulties in the environmental management, also jeopardize the implementation of preventive and control HAVL measures ${ }^{11,22}$.

However, it can still be presumed that, in general, the control measures employed in the municipalities of the Adamantina microregion were competent after the year 2010, given the subsequent decrease in HAVL incidence rates, as observed by Costa et al..$^{22}$ in Aracatuba, between 2007 and 2009. At the same time, studies that identify the places with the highest incidences and risk factors, as well as the characterization of the epidemiological regional characteristics can significantly contribute to the diagnosistreatment process ${ }^{18,28}$.

In view of the above, the georeferencing of cases in this microregion can assist in the identification of potentially high-risk regions for the occurrence of the disease, as a better understanding of the disease and its expansion 
process, under a space-time characterization, facilitates the adoption of measures aimed at controlling and preventing. Thus, understanding the spatial and temporal dissemination of HAVL and associate it to notorious environmental characteristics including the geographical space, culture, habits and socioeconomic conditions, enables to construct regional epidemiological profiles in order to develop rational control strategies.

\section{AUTHORS' CONTRIBUTIONS}

Study conception and design: Rancan EA, Matins LP, Suzuki RB; analytical calculations: Chagas EF, Rancan EA; analysis and interpretation of data: Rancan EA, Carvalho VC, Sperança MA, Martins LP, Suzuki RB; production of maps: Rancan EA; production of tables: Suzuki RB; drafting of manuscript: Rancan EA, Martins LP, Suzuki $\mathrm{RB}$, Sperança MA.

\section{CONFLICT OF INTERESTS}

The authors report that there is no conflict of interests.

\section{FUNDING}

This study was supported by the Fundação de Amparo à Pesquisa do Estado de São Paulo (FAPESP), grant No 2016/14514-4.

\section{REFERENCES}

1. Ashford RW. The leishmaniases as emerging and reemerging zoonoses. Int J Parasitol. 2000;30:1269-81.

2. Herwaldt BL. Leishmaniasis. Lancet (London, England). 1999;354:1191-9.

3. Organização Pan-Americana da Saúde. Organização Mundial da Saúde. Leishmanioses: informe epidemiológico das Américas. [cited 2020 Sep 15]. Available from: https://iris.paho.org/ bitstream/handle/10665.2/50505/2019-cde-leish-informe-epidas-americas.pdf? sequence $=2 \&$ isAllowed $=y$

4. Deane LM, Deane MP. Visceral leishmaniasis in Brazil: geographical distribution and transmission. Rev Inst Med Trop Sao Paulo. 1962;4:198-212.

5. Costa JM, Viana GM, Saldanha AC, Nascimento MD, Alvim AC, Burattini MN, et al. Leishmaniose Visceral no Estado do Maranhão, Brasil: a evolução de uma epidemia. 1995;11:321-4.

6. Costa CH, Pereira HF, Araújo MV. Epidemia de leishmaniose visceral no Estado do Piauí, Brasil, 1980-1986. Rev Saude Publica. 1990;24:361-72.

7. Rodrigues AC, Melo AC, Júnior AD, Franco SO, Rondon F, Bevilaqua CM. Epidemiologia da leishmaniose visceral no município de Fortaleza, Ceará. Pesq Vet Bras. 2017;37:111924

8. Dantas-Torres F. Situação atual da epidemiologia da leishmaniose visceral em Pernambuco. Rev Saude Publica. 2006;40:537-41.

9. Dantas-Torres F, Brandão-Filho SP. Expansão geográfica da leishmaniose visceral no Estado de Pernambuco. Rev Soc Bras Med Trop. 2006;39:352-6.

10. Brasil. Ministério da Saúde. Secretaria de Vigilância em Saúde. Departamento de Vigilância Epidemiológica. Guia de vigilância epidemiológica. $7^{\mathrm{a}}$ ed. Brasília: Ministério da Saúde; 2009.

11. von Zuben AP, Donalísio MR. Dificuldades na execução das diretrizes do Programa de Vigilância e Controle da Leishmaniose Visceral em grandes municípios brasileiros. Cad Saude Publica. 2016;32:e0087415.

12. Brasil. Ministério da Saúde. Secretaria de Vigilância em Saúde. Coordenação-Geral de Desenvolvimento da Epidemiologia em Serviços. Guia de vigilância em saúde. $2^{\mathrm{a}}$ ed. Brasília: Ministério da Saúde; 2017.

13. Brasil. Ministério da Saúde. Secretaria de Vigilância em Saúde. Vigilância em saúde no Brasil 2003/2019: da criação da Secretaria de Vigilância em Saúde aos dias atuais. Bol Epidemiol. 2019;N Esp:1-154.

14. Sevá AP, Mao L, Galvis-Ovallos F, Lima JM, Valle D. Risk analysis and prediction of visceral leishmaniasis dispersion in São Paulo State, Brazil. PLoS Negl Trop Dis. 2017;11:e0005353.

15. Casanova C, Colla-Jacques FE, Hamilton JG, Brazil RP, Shaw JJ. Distribution of Lutzomyia longipalpis chemotype populations in São Paulo state, Brazil. PLoS Negl Trop Dis. 2015;9:e0003620

16. Cardim MF, Rodas LA, Dibo MR, Guirado MM, Oliveira AM, Chiaravalloti Neto, F. Introduction and expansion of human American visceral leishmaniasis in the state of São Paulo, Brazil, 1999-2011. Rev Saude Publica. 2013;47:691-700.

17. Cardim MF, Vieira CP, Chiaravalloti-Neto, F. Spatial and spatiotemporal occurrence of human visceral leishmaniasis in Adamantina, State of São Paulo, Brazil. Rev Soc Bras Med Trop. 2015;48:716-23.

18. Barcellos CC, Sabroza PC, Peiter P, Iñiguez Rojas L. Organização espacial, saúde e qualidade de vida: análise espacial e uso de indicadores na avaliação de situações de saúde. Inf Epidemiol SUS. 2002;11:129-38.

19. Instituto Brasileiro de Geografia e Estatística. Cidades@. [cited 2020 Sep 15]. Available from: https://cidades.ibge.gov.br/

20. São Paulo. Governo do Estado. Centro Integrado de Informações Agrometeorológicas. Balanço hídrico semanal. [cited 2020 Sep 15]. Available from: http://www.ciiagro.sp.gov.br/ ciiagroonline/Listagens/BH/LBalancoHidricoLocal.asp

21. Camargo-Neves V. A leishmaniose visceral americana no estado de São Paulo: situação atual. Bol Epidemiol Paulista. 2007;4:12-4. 
22. Costa DN, Bermudi PM, Rodas LA, Nunes CM, Hiramoto RM, Tolezano JE, et al. Human visceral leishmaniasis and relationship with vector and canine control measures. Rev Saude Publica. 2018;52:92.

23. Cardim MF, Guirado MM, Dibo MR, Chiaravalloti Neto F. Leishmaniose visceral no estado de São Paulo, Brasil: análise espacial e espaço-temporal. Rev Saude Publica. 2016;50:48.

24. Souza VA, Cortez LR, Dias RA, Amaku M, Ferreira Neto JS, Kuroda RB, et al. Space-time cluster analysis of American visceral leishmaniasis in Bauru, São Paulo State, Brazil. Cad. Saude Publica. 2012;28:1949-64.

25. Toledo CR, Almeida AS, Chaves SA, Sabroza PC, Toledo LM, Caldas JP. Vulnerability to the transmission of human visceral leishmaniasis in a Brazilian urban area. Rev Saude Publica. 2017;51:49.

26. Macedo IT, Bevilaqua CM, Morais N, Sousa L, Linhares F, Amóra SS, et al. Sazonalidade de flebotomíneos em área endêmica de leishmaniose visceral no município de Sobral, Ceará, Brasil. Cien Anim. 2008;18:67-74.

27. Martins KP, Garcia DA, Cortezi AM, Gomes DE. Escorpionismo: revisão de literatura. Rev Cien. 2018;1.

28. Vieira CP, Oliveira AM, Rodas LA, Dibo MR, Guirado MM, Chiaravalloti Neto F. Temporal, spatial and spatiotemporal analysis of the occurrence of visceral leishmaniasis in humans in the City of Birigui, State of São Paulo, from 1999 to 2012. Rev Soc Bras Med Trop. 2014;47:350-8.

29. Alves WA, Fonseca DS. Leishmaniose visceral humana: estudo do perfil clínico-epidemiológico na região leste de Minas Gerais, Brasil. J Health Biol Sci. 2018;6:133-9.

30. Ortiz RC, Anversa LJ. Epidemiologia da leishmaniose visceral em Bauru, São Paulo, no período de 2004 a 2012: um estudo descritivo. Epidemiol Serv Saude. 2015;24:97-104.

31. Madalosso G, Fortaleza CM, Ribeiro AF, Cruz LL, Nogueira PA, Lindoso JA. American visceral leishmaniasis: factors associated with lethality in the state of São Paulo, Brazil. J Trop Med. 2012;2012:281572.
32. Moura GS, Santos AM, Aquino DM, Silva AA, Caldas AJ. Factors associated with asymptomatic infection in family members and neighbors of patients with visceral leishmaniasis. Cad Saude Publica. 2012;28:2306-14.

33. Brazuna JC, Silva EA, Brazuna JM, Domingos IH, Chaves N, Honer MR, et al. Profile and geographic distribution of reported cases of visceral leishmaniasis in Campo Grande, State of Mato Grosso do Sul, Brazil, from 2002 to 2009. Rev Soc Bras Med Trop. 2012;45:601-6.

34. Queiroz MJ, Alves JG, Correia JB. Visceral leishmaniasis: clinical and epidemiological features of children in an endemic area. J Pediatr. 2004;80:141-6.

35. Oliveira JM, Fernandes AC, Dorval ME, Alves TP, Fernandes TD, Oshiro ET, et al. Mortalidade por leishmaniose visceral: aspectos clínicos e laboratoriais. Rev Soc Bras Med Trop. 2010;43:188-93.

36. Santos MA, Rodrigues SL, Nascimento AL, Rodrigues JS, Góes MA. Leishmaniose Visceral: características clínicoepidemiológicas de casos e óbitos no estado de Sergipe. Rev Epidemiol Controle Infecç. 2018;8:428-34.

37. Lopes EG, Magalhães DF, Silva JA, Haddad JP, Moreira EC. Distribuição temporal e espacial da leishmaniose visceral em humanos e cães em Belo Horizonte-MG, 1993 a 2007. Arq Bras Med Vet Zootec. 2010;62:1062-71.

38. Brasil. Ministério da Saúde. Secretaria de Vigilância em Saúde. Departamento de Vigilância Epidemiológica. Manual de vigilância e controle da leishmaniose visceral. Brasília: Ministério da Saúde; 2014.

39. Camargo-Neves VL, Katz G, Rodas LA, Poletto DW, Lage LC, Spínola RM, et al. Utilização de ferramentas de análise espacial na vigilância epidemiológica de leishmaniose visceral americana-Araçatuba, São Paulo, Brasil, 1998-1999. Cad Saude Publica. 2001;17:1263-7. 